\title{
Selection of reference genes for gene expression studies in ultraviolet B-irradiated human skin fibroblasts using quantitative real-time PCR
}

\author{
Li Li', Yan Yan', Haoxiang Xu², Tao Qu', Baoxi Wang ${ }^{2 *}$
}

\begin{abstract}
Background: Reference genes are frequently used to normalise mRNA levels between different samples. The expression level of these genes, however, may vary between tissues or cells and may change under certain circumstances. Cytoskeleton genes have served as multifunctional tools for experimental studies as reference genes. Our previous studies have demonstrated that the expression of vimentin, one cytoskeletal protein, was increased in ultraviolet B (UVB)-irradiated fibroblasts. Thus, we examined the expression of other cytoskeleton protein genes, ACTB (actin, beta), TUBA1A (tubulin, alpha 1a), and TUBB1 (tubulin, beta 1), in human dermal fibroblasts irradiated by UVB to determine which of these candidates were the most appropriate reference genes.

Results: Quantitative real-time PCR followed by analysis with the NormFinder and geNorm software programmes was performed. The initial screening of the expression patterns demonstrated that the expression of VIM was suppressed after UVB irradiation at doses $\geq 25 \mathrm{~mJ} / \mathrm{cm}^{2}$ and that the expression of TUBATA was significantly reduced by UVB doses $\geq 75 \mathrm{~mJ} / \mathrm{cm}^{2}$ in cultured human dermal fibroblasts. The analysis of the experimental data revealed ACTB to be the most stably expressed gene, followed by GAPDH (aglyceraldehyde-3-phosphate dehydrogenase), under these experimental conditions. By contrast, VIM was found to be the least stable gene. The combination of $A C T B$ and TUBB1 was revealed to be the gene pair that introduced the least systematic error into the data normalisation.

Conclusion: The data herein provide evidence that ACTB and TUBB1 are suitable reference genes in human skin fibroblasts irradiated by UVB, whereas VIM and TUBATA are not and should therefore be excluded as reference genes in any gene expression studies involving UVB-irradiated human skin fibroblasts.
\end{abstract}

\section{Background}

Ultraviolet B (UVB) radiation is the most active, albeit minor, constituent of solar light. UVB has both direct and indirect adverse biological effects that may result in photo-aging and photo-carcinogenesis. The DNA damage caused by UVB irradiation is considered to be responsible for basal cell carcinoma and squamous cell carcinoma $[1,2]$. UVB is also suspected of lowering the immune defence system of the skin [3]. Given these effects, the gene expression of dermal fibroblasts after UVB irradiation has become a significant area of study,

\footnotetext{
*Correspondence: wangbx1583@263.com

${ }^{2}$ Chinese Academy of Medical Sciences and Peking Union Medical College Institute of Dermatology, Nanjing, PR China

Full list of author information is available at the end of the article
}

with a total of 384 manuscripts found in PubMed using the keyword 'UVB' just within the last year.

Quantitative real-time PCR (qPCR) is the most powerful method used to quantify gene expression. Similar to other expression study methods, the sample data are usually required to be normalised against either another data set or particular references to correct for any differences in the amount of starting material. At present, the most common normalisation method involves the use of a single internal control reference gene, often selected from a set of genes referred to as 'housekeeping' genes that are constitutively expressed in certain tissues and/ or under certain circumstances. There is strong evidence in the literature, however, to suggest that the expression of some of these reference genes may be constant under certain conditions but may also fluctuate significantly

\section{C) Biomed Central}


under other conditions $[4,5]$. Commonly accepted reference genes, such as ACTB (actin, beta) and GAPDH (aglyceraldehyde-3-phosphate dehydrogenase), have been shown to be affected by particular in vitro experimental conditions and some clinical conditions, such as asthma [6], thus indicating that they may not always be suitable candidates for normalisation [7]. The normalisation of data using a non-validated reference gene could lead to inaccurate results and therefore erroneous conclusions. Previous studies have reinforced the need to validate reference genes prior to their use in a study. Cytoskeletal protein genes, including $A C T B, T U B A 1 A$ (tubulin, alpha 1a), and TUBB1 (tubulin, beta 1), have been used as reference genes for many experimental conditions.

The cytoskeleton is the cellular 'scaffolding' or 'skeleton' that is contained within the cytoplasm. Its concept and term (cytosquelette, in French) were first introduced by the French embryologist Paul Wintrebert in 1931 [8]. The cytoskeleton is composed of three types of protein filaments: actin filaments, intermediate filaments and microtubules [9]. The cytoskeleton was once thought to be unique to eukaryotes, but recent research has identified a prokaryotic cytoskeleton [10]. The cytoskeleton is a dynamic structure that maintains cell shape, protects the cell, enables cellular movement, and plays important roles in both intracellular transport and cell division $[11,12]$. Not only is it an indispensable protein complex for all cells, including eukaryotes and prokaryotes, but it also serves as a multifunctional tool because many of its proteins can be used as reference genes for a variety of experimental studies.

Our previous studies have demonstrated that fibroblasts increased the expression of vimentin, a cytoskeleton protein, after irradiation by UVB [13]. Whether the expression levels of other cytoskeletal genes, such as $A C T B, T U B A 1 A$, and TUBB1, are altered after UVB irradiation and consequently whether any of these genes are suitable reference genes remain unknown. In this study, primary human dermal fibroblasts were treated with different doses of UVB radiation, and the irradiated cells were analysed at different time points. The gene expression of four cytoskeletal genes (Table 1) after irradiation was compared with another common reference gene, GAPDH. These five genes were also analysed with respect to their suitability as reference genes for expression studies in healthy and irradiated fibroblasts. To define the most stable reference genes for these study conditions, the expression changes between and within these two groups were investigated and analysed using two software products available free online.

\section{Results}

\section{Assessment of pre-analytical and analytical variables}

The determination of the primary cell type was the basis of these experiments. Fibroblasts express vimentin, whereas keratinocytes express keratin. Thus, the cells isolated from the foreskin samples were examined to determine if vimentin and/or keratin were expressed at both the mRNA transcript and protein levels. In fibroblasts, PCR results in a bright, specific band for the vimentin primers but no specific products for the keratin 10 primers by $2 \%$ agarose gel electrophoresis analysis. The opposite pattern was seen in the $\mathrm{HaCaT}$ keratinocyte cell line (Figure 1). Fibre bundles in the cytoplasm along the cell axis stained green, while the nucleus stained orange by fluorescent immunohistochemical analysis in fibroblasts(Figure 2). These same fibroblasts were negative for the expression of the keratin protein (data not shown). Taken together, these results indicated that highly pure human dermal fibroblasts were successfully obtained from the foreskin samples.

In RT-qPCR experiments, there are many pre-analytical variables, including the collection and storage of samples and the RNA isolation method, that determine the quality of the RNA that is used for the subsequent quantitative expression analyses. Therefore, the RNA samples isolated from the 12 matched normal and irradiated fibroblasts were characterised with respect to their concentration, purity, and integrity. Only high quality RNA samples were included in this study to avoid erroneous conclusions. The mean A260/280 ratio of the RNA samples was $2.01 \pm$ 0.037 (range: $1.93-2.08$ ), reflecting pure and protein-free

Table 1 Characteristics of the five reference gene candidates analysed in this study

\begin{tabular}{|c|c|c|c|c|c|}
\hline $\begin{array}{l}\text { Gene } \\
\text { symbol }\end{array}$ & Gene name & $\begin{array}{l}\text { Accession } \\
\text { No. }\end{array}$ & Function & Gene aliases & Locus \\
\hline GAPDH & $\begin{array}{l}\text { aglyceraldehyde-3-phosphate } \\
\text { dehydrogenase }\end{array}$ & NM_002046.3 & Glycolytic enzyme & G3PD;GAPD & $12 \mathrm{p} 13$ \\
\hline$A C T B$ & actin, beta & NM_001101.3 & $\begin{array}{l}\text { The contractile apparatus and nonmuscle } \\
\text { cytoskeletal actins }\end{array}$ & PS1TP5BP1 & 7p15-p12 \\
\hline TUBA1A & tubulin, alpha 1a & NM_006009.2 & The components of microtubules & $\begin{array}{l}\text { LIS3; TUBA3; FLJ25113; B- } \\
\text { ALPHA-1 }\end{array}$ & $\begin{array}{l}12 \mathrm{q} 12^{-} \\
\mathrm{q} 14.3\end{array}$ \\
\hline TUBB1 & tubulin, beta 1 & NM_030773.2 & the components of microtubules & dJ543J19.4 & $20 q 13.32$ \\
\hline VIM & vimentin & NM_003380.2 & $\begin{array}{l}\text { maintaining cell shape, integrity of the } \\
\text { cytoplasm }\end{array}$ & FLJ36605 & 10p13 \\
\hline
\end{tabular}




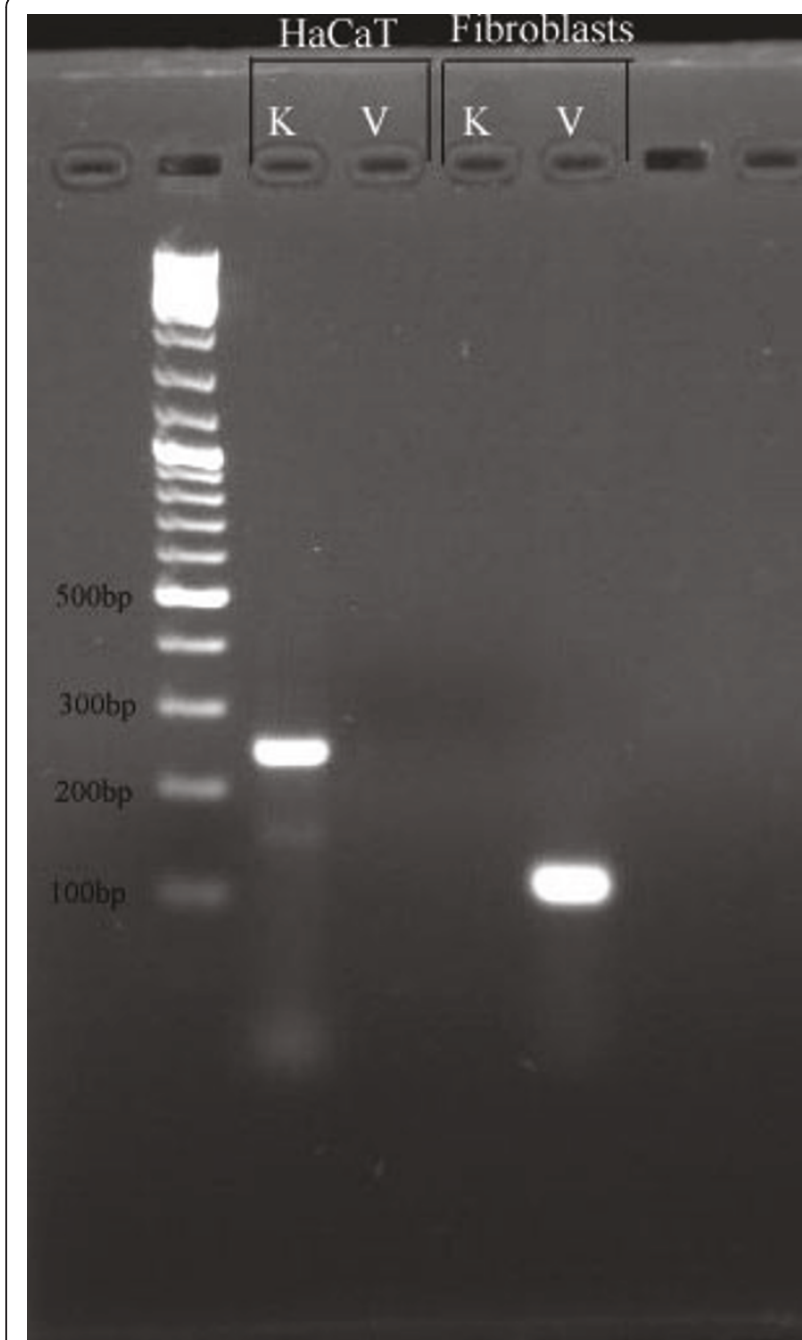

Figure 1 Detection of VIM and keratin 10 by standard PCR in primary fibroblasts and the HaCaT cell line. $\mathrm{V}$ : the expression of $V I M, K$ : the expression of keratin 10.

RNA. The RNA integrity as an essential quality criterion was characterised using the so-called RNA integrity number (RIN), measured by the Agilent 2100 Bioanalyzer. The mean RIN value $( \pm$ SD) of the RNA samples was $9.3 \pm$ 0.57 (range: 8.0 - 10.0).

Pooled cDNA samples were used as a precision control for each gene-specific PCR run. These controls were adjusted to calculate the PCR efficiency as described in the methods. The mean PCR efficiencies varied from 0.967 to 1.06 (Table 1 ). The between-run analytical performances of the RT-PCR measurements were determined using these controls, and the betweenrun variations $(\mathrm{n}=5)$ ranged from $0.17 \%$ to $0.38 \%$. The standard deviation (SD) for the triplicate reactions ranged from 0.023 to 0.751 cycles (mean $=0.31$ cycles).

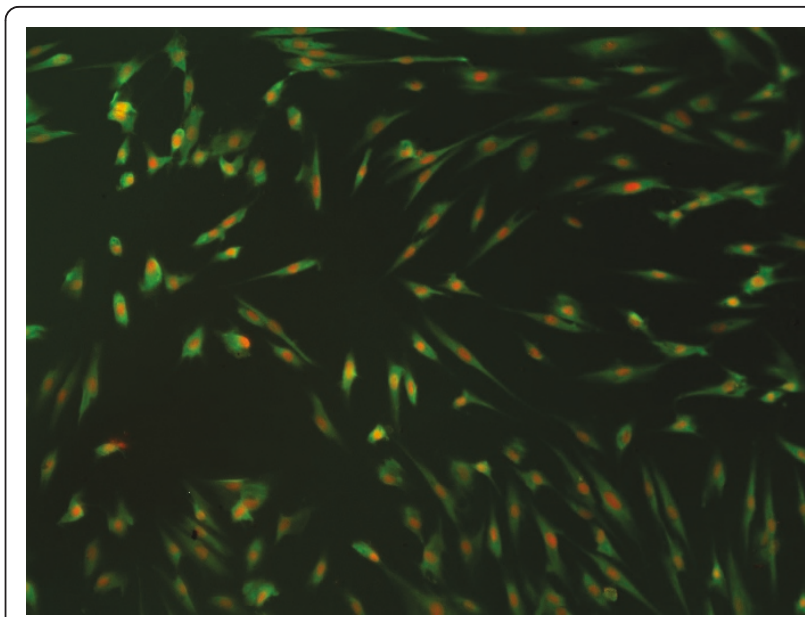

Figure 2 Vimentin expression in cultured human dermal fibroblasts. Vimentin staining (green) was positive by immunohistochemical analysis, showing its localisation to the nucleus. The cytoplasm was stained orange. Magnification $=\times 20$.

\section{UVB suppressed the expression of TUBA1A and VIM in} cultured human dermal fibroblasts

To determine whether UVB affects the expression of cytoskeletal genes in cultured human fibroblasts, the fibroblasts were exposed to various doses of UVB (25, 50,75 , and $100 \mathrm{~mJ} / \mathrm{cm}^{2}$ ). After UVB irradiation, the fibroblasts were cultured for $24 \mathrm{~h}$, and then total RNA was extracted from the cells. qPCR was performed to determine the changes in the expression of these cytoskeletal genes. As common reference genes, the expression levels of $A C T B, G A P D H$ and TUBB1 were not significantly different between the normal and irradiated fibroblasts (data not shown). Doses of 25 and $50 \mathrm{~mJ} /$ $\mathrm{cm}^{2}$ did not alter the expression levels of TUBA1A (Figure 3-A), but they were significantly reduced at doses $\geq 75 \mathrm{~mJ} / \mathrm{cm}^{2}(P<0.05)$. The expression of VIM began to be significantly reduced after exposure to a UVB dose of $25 \mathrm{~mJ} / \mathrm{cm}^{2}(P<0.05$; Figure $4-\mathrm{A})$. The decreased expression of VIM became even more pronounced at doses of 75 and $100 \mathrm{~mJ} / \mathrm{cm}^{2}$ when compared with 25 and $50 \mathrm{~mJ} / \mathrm{cm}^{2}(P<0.05)$. The mRNA expression levels of TUBA1A and VIM were reduced by varied UVB intensities.

To determine whether the time after exposure to UVB affects the expression of cytoskeletal protein genes in cultured human fibroblasts, total RNA was extracted at different time points $(12,24,36$, and $48 \mathrm{~h})$ after exposure to a $125 \mathrm{~mJ} / \mathrm{cm}^{2}$ UVB dose. This dose did not have a significant effect on the expression levels of GAPDH, $A C T B$ and $T U B B 1$ at the time points up to $48 \mathrm{~h}$ postirradiation (data not shown). The expression of TUBA1A didn't show statistically significant difference at the $12,24,36,48 \mathrm{~h}$ though it was decreased by 125 

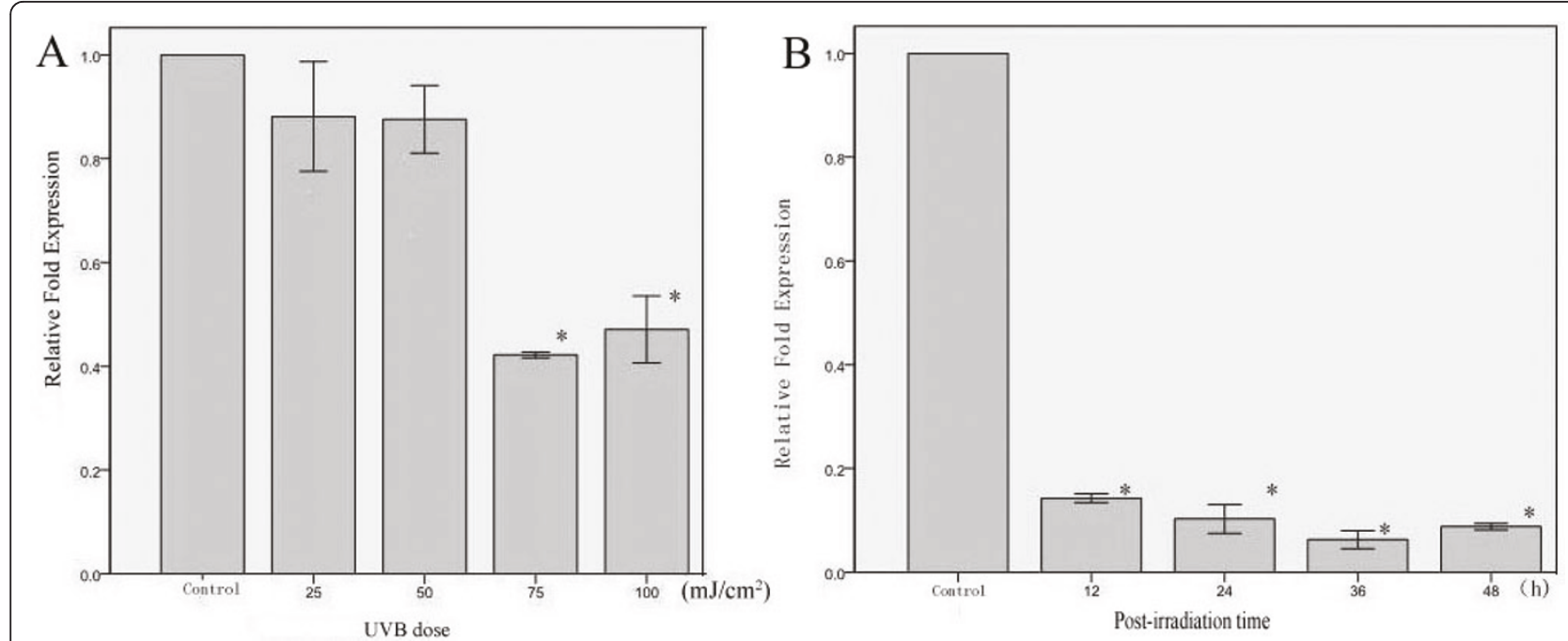

Figure 3 The relative fold expression of TUBA1A in fibroblasts irradiated by UVB at the indicated time points. (Figure 3-A) TUBATA expression in fibroblasts $24 \mathrm{~h}$ after treatment with different does of UVB, including $0,25,50,75$, and $100 \mathrm{~mJ} / \mathrm{cm}^{2}$. (Figure 3-B) The time course of TUBATA expression after treatment with $125 \mathrm{~mJ} / \mathrm{cm}^{2}$ UVB. The error bars represent the standard deviation. The experiments were performed in triplicate. ${ }^{*} p<0.05$ compared with the control group.

$\mathrm{mJ} / \mathrm{cm}^{2}$ of UVB (Figure 3-B). T. The VIM mRNA level decreased after exposure to a UVB dose of $125 \mathrm{~mJ} / \mathrm{cm}^{2}$ $(P<0.05)$, and this decrease appeared to be time dependent, with greater decreases seen after 36 and $48 \mathrm{~h}$ compared with those seen at 12 and 24 h post-exposure $(P<$ 0.05; Figure 4-B). Thus, neither TUBA1A nor VIM is a suitable reference gene for research involving UVB-irradiated human fibroblasts.

\section{Expression levels and ranges of the reference gene candidates}

Although the expression levels of TUBA1A and VIM were significantly reduced in fibroblasts after exposure to UVB, they were still evaluated as potential reference genes along with $A C T B, G A P D H$ and TUBB1. The expression levels of these five candidates (Table 2), shown in terms of Ct-values, are given as box-and-
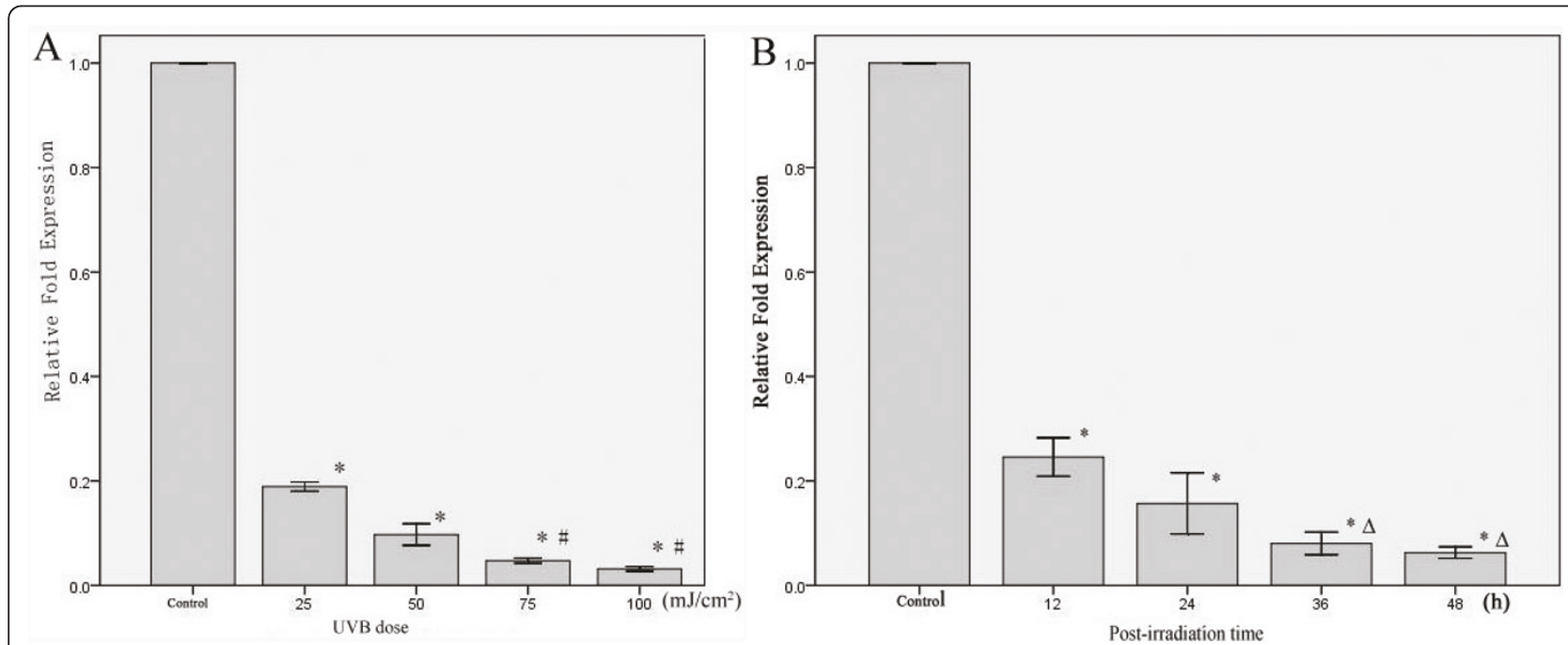

Figure 4 The relative fold expression of VIM in fibroblasts irradiated by UVB at the indicated time points. (Figure 4-A) VIM expression in fibroblasts $24 \mathrm{~h}$ after treatment with different does of UVB, including $0,25,50,75$, and $100 \mathrm{~mJ} / \mathrm{cm}^{2}$. (Figure 4-B) The time course of VIM expression after treatment with $125 \mathrm{~mJ} / \mathrm{cm}^{2}$ UVB. The error bars represent the standard deviation. The experiments were performed in triplicate. ${ }^{*} p<0.05$ compared with the control groups; $\# p<0.05$ compared with the group irradiated with a dose of $50 \mathrm{~mJ} / \mathrm{cm}^{2} ; \Delta p<0.05 \mathrm{compared}$ with the group $24 \mathrm{~h}$ after exposure. 
Table 2 Sequences and related information of the primers

\begin{tabular}{|c|c|c|c|c|c|}
\hline $\begin{array}{l}\text { Gene } \\
\text { symbol }\end{array}$ & Primer sequence $^{a}$ & $\begin{array}{l}\text { Amplicon length } \\
\text { (bp) }\end{array}$ & $\begin{array}{l}\text { Annealing temperature } \\
\left({ }^{\circ} \mathrm{C}\right)\end{array}$ & PCR efficiency ${ }^{\mathrm{b}} / \mathrm{E}$ & $R$ \\
\hline$\overline{G A P D H}$ & $\begin{array}{l}\text { F: ACAGTCAGCCGCATCTTCTT } \\
\text { R: GTTAAAAGCAGCCCTGGTGA }\end{array}$ & 127 & 57 & 1.001 & 0.999 \\
\hline ACTB & $\begin{array}{l}\text { F: GGCGGCAACACCATGTACCCT } \\
\text { R: AGGGGCCGGACTCGTCATACT }\end{array}$ & 205 & 62 & 1.06 & 0.95 \\
\hline TUBA1A & $\begin{array}{l}\text { F: GCAACAACCTCTCCTCTTCG } \\
\text { R: GAATCATCTCCTCCCCCAAT }\end{array}$ & 200 & 57 & 1.043 & 0.991 \\
\hline TUBB 1 & $\begin{array}{l}\text { F: CCTTGCAGCTGGAGAGAATC } \\
\text { R: CTGTCGGGTTGAAGAGAGC }\end{array}$ & 145 & 59 & 0.967 & 1.00 \\
\hline VIM & $\begin{array}{l}\text { F: GACAGGATGTTGACAATGCG } \\
\text { R: GTTCCTGAATCTGAGCCTGC }\end{array}$ & 135 & 59 & 1.03 & 0.998 \\
\hline K10 & $\begin{array}{l}\text { F: GCCAACATCCTGCTTCAGAT } \\
\text { R: TCACATCACCAGTGGACACA }\end{array}$ & 256 & 58 & & \\
\hline
\end{tabular}

${ }^{a}$ All primer sequences are given in the $5^{\prime} \rightarrow 3^{\prime}$ direction.

${ }^{b}$ PCR efficiencies were determined by PCR DataMiner and confirmed by a dilution series experiment.

whisker plots in Figure 5. The boxes represent the median Ct-values and the inter-quartile ranges, while the whiskers indicate the min-max ranges. Genes with higher expression levels show lower Ct-values under the specific PCR conditions, and genes with lower expression levels have inversely higher cycle numbers. The five candidate reference genes showed a wide range of expression levels with $\mathrm{Ct}$ values falling between 12 and 34 cycles. The median $\mathrm{Ct}$ values were in the range usually covered by reference genes, varying from 16.48 (GAPDH) to 29.75 (TUBB1). The genes could be divided into two groups: a group of genes with a median $\mathrm{Ct}$ value below 20

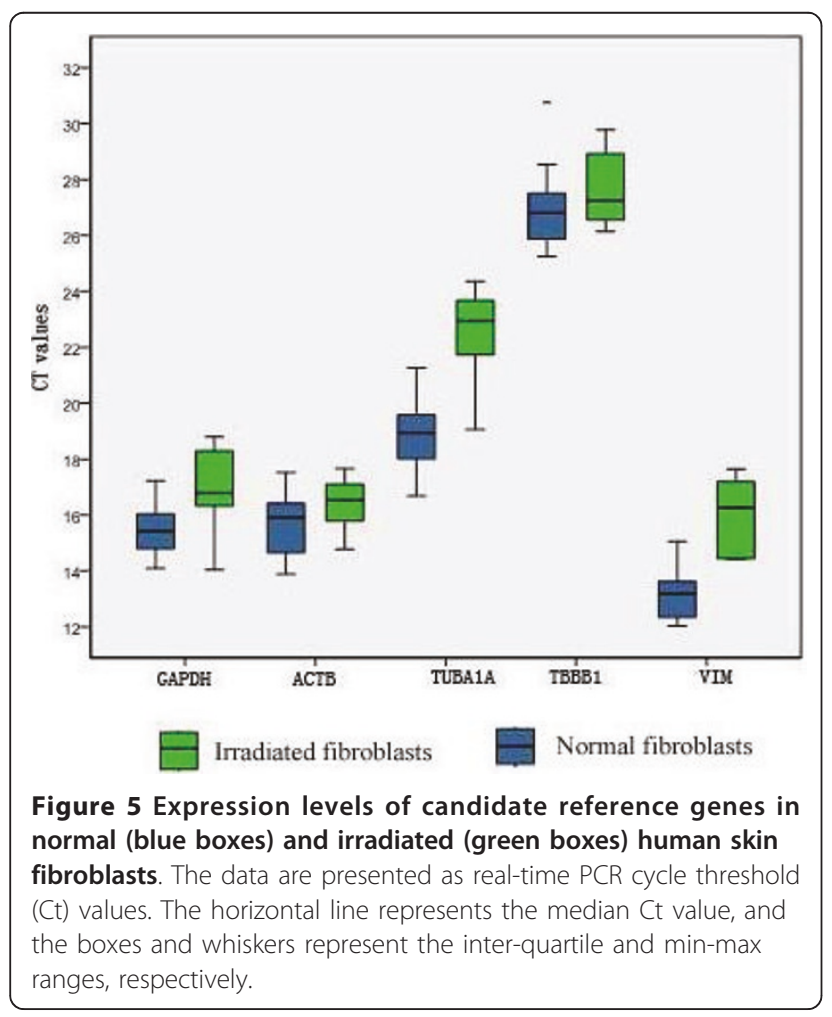

(GAPDH and ACTB, VIM) or above 20 (TUBA1A, $T U B B 1$ ) (Figure 5). There was a trend of higher median $\mathrm{Ct}$ values of all reference genes in irradiated fibroblasts compared to normal fibroblasts. However, the difference was not big enough to conclude that the $A C T B, G A P D H$, and TUBB1 expression levels differed between normal and irradiated fibroblasts. TUBA1A and VIM had significantly different expression levels in normal and irradiated fibroblasts $(P<0.01)$. Individual candidate reference genes also showed different expression ranges across all studied samples. TUBB1 and ACTB showed the smallest $C t$ value variability in normal (min-max range: 1.17 ) and irradiated (min-max range: 3.4 ) fibroblasts, respectively, while TUBA1A (min-max range: 3 ) and TUBA1A (minmax range: 7.07 ) showed the largest variance in normal and irradiated fibroblasts.

\section{Expression stability of reference gene candidates}

The NormFinder algorithm was used to rank the five irradiated fibroblast reference gene candidates according to their expression stability (Figure 6). As revealed by the analysis, $A C T B$, characterised by the stability value of 0.128 , had the most stable expression levels and thus was selected by the algorithm as the best choice for a

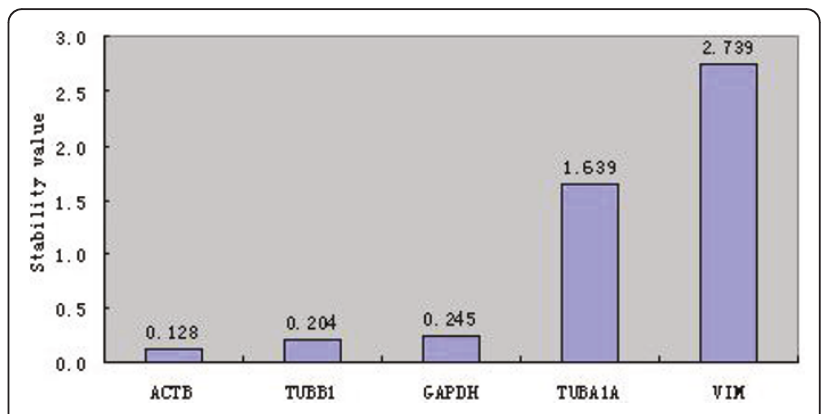

Figure 6 The average value of expression stability of each gene determined using the NormFinder software. 
single reference gene for expression studies in normal and irradiated fibroblasts. TUBB1 and GAPDH were ranked as the second- and third-best reference genes, respectively. Two commonly used reference genes, TUBA1A and VIM, were ranked last, suggesting that they should not be considered as reliable reference genes for expression assay studies involving fibroblasts. The programme additionally identified $A C T B$ and TUBB1 as the best combination of two reference genes.

NormFinder can also be used to calculate the intragroup variation. The variation of the five candidate genes in normal and matched irradiated fibroblast pairs are presented in Table 3. The variation of ACTB in the normal and matched irradiated fibroblasts was the lowest, whereas TUBA1A and VIM had the largest variance. The expression of VIM began to be significantly reduced after exposure to a UVB dose of $25 \mathrm{~mJ} / \mathrm{cm}^{2}$, with an even more pronounced reduction at 75 and $100 \mathrm{~mJ} /$ $\mathrm{cm}^{2}$, which may explain the variance of VIM expression seen in the irradiated fibroblasts.

The expression level stability of the candidate genes in normal and irradiated fibroblasts was also investigated using the geNorm programme. The curve presented in Figure 7 represents the stepwise exclusion of the least stable candidate reference gene. This algorithm confirmed the results obtained by NormFinder, showing that TUBA1A and VIM were the least stable reference genes, while the combination of $A C T B$ and TUBB1 was the most stable gene pair $(M=0.37)$.

The geNorm analysis also allows for evaluation of the optimal number of reference genes required for a reliable and accurate normalisation of expression data. It is suggested that the $\mathrm{Vn} / \mathrm{Vn}+1$ cut-off value of 0.15 should be considered as a limit beneath which the involvement of additional reference genes would not be required [14]. However, based on our experimental data, the variation $\mathrm{Vn} / \mathrm{Vn}+1$ did not reach this cut-off; the observed variability ranged from 0.221 for the addition of a third reference gene $(n=2)$ to 0.798 for the addition of five reference genes $(n=4)$ (Figure 8$)$. With the increase in the number of genes, the variation $\mathrm{Vn} / \mathrm{Vn}+1$ did not decrease. This may be related to the changes in TUBA1A and VIM.

Table 3 The intragroup variation as determined by the Norm Finder software for each gene

\begin{tabular}{lcc}
\hline & \multicolumn{2}{c}{ Intragroup variation } \\
\hline Gene name & Normal fibroblasts & Irradiated fibroblasts \\
GAPDH & 0.026 & 0.511 \\
ACTB & 0.012 & 0.036 \\
TUBA1A & 0.05 & 5.284 \\
TUBB1 & 0.02 & 0.046 \\
VIM & 0.038 & 7.535 \\
\hline
\end{tabular}

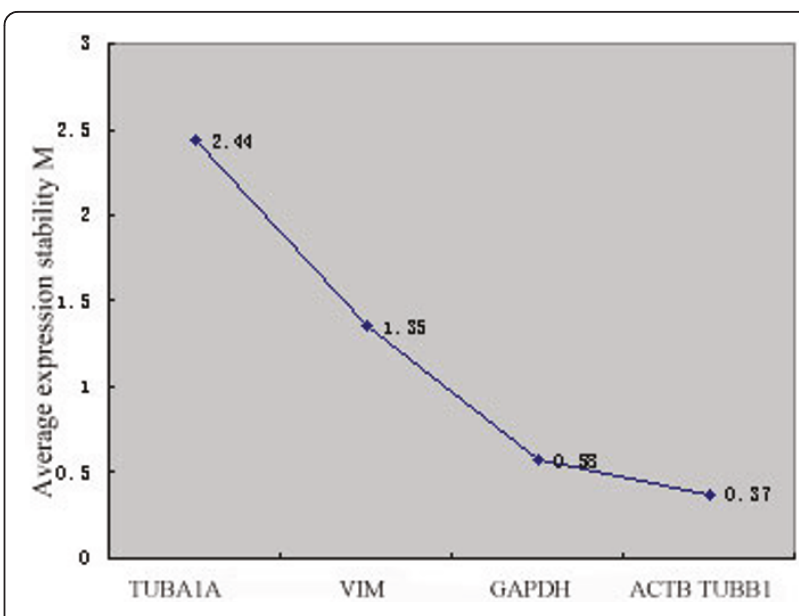

Figure 7 The stepwise exclusion of least stable genes by calculating the average $M$ value. The average value of the expression stability $\mathbf{M}$ for each gene was determined using geNorm software. Genes on the x-axis are ordered from the left to the right according to their expression stability from the least to the most stable.

\section{Discussion}

The fluorescence-based quantitative real-time PCR (qPCR) has the capacity to detect and measure minute amounts of nucleic acids in a wide range of samples from numerous sources, enabling it to be the technology par excellence for multiple applications in molecular diagnostics, life sciences, agriculture, and medicine $[4,5]$. The remarkable lack of consensus on the best qPCR methods for different experiments, however, has the adverse consequence of perpetuating a string of serious shortcomings that encumber its status as an independent yardstick. In 2008, a set of "MIQE" guidelines were

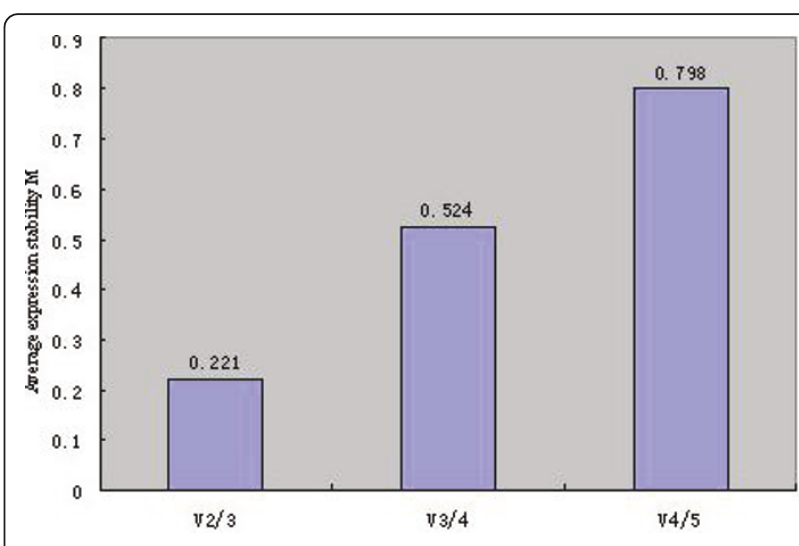

Figure 8 Evaluation of the optimum number of reference genes according to the geNorm software. The magnitude of the change in the normalisation factor after the inclusion of an additional reference gene reflects the improvement that is obtained. $\mathrm{Vn} / \mathrm{n}+1$ represents a comparison of the different models, which are those with $n$ and $n+1$ reference genes. 
proposed to establish a minimum standard for the required information that should be included in publications utilising qPCR experiments [1]. In the experiment described herein, we adhered to the MIQE guidelines to the best of our abilities. The RNA extracted from the primary fibroblasts was validated by immunofluorescence, with its quantity, quality and integrity subsequently determined. All RNA meeting the minimum experimental standards was stored at $-80^{\circ} \mathrm{C}$ and was utilised within two month. Primer specificity was confirmed by melting curve analyses. PCR efficiency plots were calculated using a standard curve with the coefficient of correlation ( $\mathrm{r}$ ) between 0.95 and 1.0, and the PCR efficiency of all primers used in this study varied from 0.967 to 1.06. To ensure consistency between reactions, the same quantity of RNA was used, and both RT and $\mathrm{qPCR}$ were performed in triplicate. All of these steps ensured the reliability of this experiment and the comparability of the statistical data that was generated.

Another important factor that may affect qPCR results is the selection of the reference genes. $A C T B, \mathrm{GAPDH}$, $18 \mathrm{~S}$ and $28 \mathrm{~S}$ rRNA are the most commonly used reference genes, but a number of studies have provided solid evidence that their transcription levels vary significantly among different individuals, cell types, developmental stages, and/or experimental conditions $[15,16]$. Herein, our aim was to identify genes with the lowest expression variability and validate their use for qPCR data normalisation in expression studies on irradiated fibroblasts, employing two different techniques. To the best of our knowledge, this study is the first to analyse the expression stability of reference gene candidates in fibroblasts exposed to UVB radiation. Our previous studies demonstrated that the expression of vimentin, a cytoskeletal protein, was increased in fibroblasts after UVB irradiation. Thus, this study focused on cytoskeletal proteins commonly used as references, which were $A C T B$, TUBA1A, TUBB1, and VIM, in addition to another common reference gene, GAPDH.

The two approaches used to analyse the expression stability of the selected reference genes in our study were geNorm and NormFinder. The geNorm application measures gene expression stability $(M)$, which is the mean pairwise variation between an individual gene and all other tested reference genes. During this analysis, the least stable genes (with the highest $M$ values) were sequentially eliminated until only the two most stable genes remained. In addition, the geNorm programme can determine the optimal number of genes required for accurate normalisation by calculating pair-wise variations between consecutively determined normalisation factors of $\mathrm{n}$ and $\mathrm{n}+1$ genes $[\mathrm{V} \mathrm{n} /(\mathrm{n}+1)]$. In the original publication describing geNorm [16], a threshold of 0.15 was established for the pairwise variation, below which the inclusion of additional reference genes is considered to be unnecessary. NormFinder, which is rooted in a mathematical model of gene expression, uses a solid statistical framework to estimate not only the overall expression variation of the normalisation gene candidates, but also the variation between subgroups within a sample set (e.g., normal and cancer samples).

In this study, $A C T B$ had the most stable expression, making it the most suitable reference gene for qPCR data normalisation in normal and irradiated fibroblasts. Surprisingly, GAPDH, which is one of the most commonly used endogenous controls, was the third most stable gene in this study. There has been an increasing number of reports in the literature documenting the variability of the levels of GAPDH mRNA under a variety of physiological and pathological conditions $[17,18]$. The use of $G A P D H$ as a reference gene in the majority of tumour types, including melanoma, has recently been challenged [19]. TUBA1A is also commonly used as an endogenous control. In this study, however, the expression of TUBA1A decreased after UVB exposure using doses greater than $75 \mathrm{~mJ} / \mathrm{cm}^{2}$, making it unsuitable as a reference gene for research involving irradiated fibroblasts. Among the examined reference gene candidates, TUBA1A lies in the middle with respect to its suitability as a reference gene. A separate study by Spanier KI determined that TUBA1A was a particularly ill-suited reference gene in the Daphnia Pulex genome sequence [20].

In other studies involving qPCR, there was a trend towards the use of more than one reference gene. As described above, the geNorm programme can determine the optimal number of reference genes required for the reliable and accurate normalisation of expression data, with the $\mathrm{Vn} / \mathrm{Vn}+1$ cut-off value, which indicates the threshold at which additional reference genes are considered unnecessary, being set at 0.15 [14]. The V2/V3 value of 0.221 obtained in this study was close to the cut-off value of 0.15 . The $\mathrm{Vn} / \mathrm{n}+1$ value presented an unusual trend in our study, with V2/V3 giving the lowest value. This observation was likely due to the changes seen in the expression levels of TUBA1A and VIM.

Although our previous studies have shown that the protein expression levels of vimentin were increased in fibroblasts, our results herein showed that the VIM mRNA expression level was reduced by UVB irradiation. These two observations appear to contradict each other, and the underlying mechanism for these differences is unclear. Many studies have shown that vimentin cleavage has an impact on the integrity and the dynamics of the intracellular structures that are targets of destruction during apoptosis [21]. Based on that data, we speculate that the over-accumulation of the vimentin protein is one of the factors that contribute to the resistance of skin fibroblasts against environmental stresses. In 
addition, although TUBA1A expression was significantly reduced by exposure to UVB at doses greater than 75 $\mathrm{mJ} / \mathrm{cm}^{2}$, there was no apparent change in the levels of the TUBA1A protein. Unfortunately, these results do not provide any insight as to whether the changes in the VIM and TUBA1A expression levels correlate with ultraviolet radiation-induced skin damage. Cytoskeletondeficient cells could be used to detect interactions of the cytoskeleton with the corresponding proteins and the signal transduction pathway involved in the response to UVB irradiation.

\section{Conclusion}

Based on our results, the expression of the TUBA1A and VIM transcripts decreased in fibroblasts after UVB exposure, and thus, they were not suitable for use as reference genes. Instead, we recommend that $A C T B$ be used as a single reference gene for qPCR data normalisation in gene expression studies in normal and irradiated fibroblasts. The addition of TUBB1 to ACTB for use as a pair of reference genes is recommended for more accurate normalisation. Finally, we emphasise that the utility of the selected reference gene(s) must be confirmed by each research group for each particular experimental setup.

\section{Methods}

\section{Primary fibroblast culture}

Normal human dermal fibroblasts were obtained from the foreskin of healthy donors. The donor group comprised 24 individuals between the ages of 18 and 30 (mean age $=23$ ). All donors provided informed consent prior to their participation in the study. The study protocol was reviewed and approved by the ethics committee of Peking Union Medical College Hospital.

To obtain the fibroblasts, the foreskin was first incubated overnight in $0.25 \%$ trypsin. After separation from the epidermis using sterile tweezers, the dermis was cut into pieces to disperse the cells and obtain a single-cell suspension. Cell suspensions from two of the healthy donors were then mixed. The resulting fibroblasts were cultured in Dulbecco's Modified Eagle's Medium (DMEM; Gibco, USA) supplemented with 10\% (v/v) heat-inactivated foetal bovine serum (FBS; Bovogen, Australia), 100 $\mathrm{U} / \mathrm{ml}$ penicillin and $100 \mathrm{mg} / \mathrm{ml}$ streptomycin (Invitrogen, USA) in a $\mathrm{CO}_{2}$ incubator $\left(5 \% \mathrm{CO}_{2}\right)$ at $37^{\circ} \mathrm{C}$. The experiments were performed on fibroblasts at 3 to 6 passages. For the irradiation experiments, the cells were seeded in 6 $\mathrm{cm}$ Petri dishes and grown to $80 \%$ confluence.

\section{Identification of primary fibroblasts and associated transcript and protein levels}

Total RNA was extracted from the fibroblasts and reversetranscribed into cDNA. Primers for VIM and keratin 10
(K10) were designed and synthesised. A detailed description of the primer design process is given below (see 'Primer design'). Standard PCR was then performed. Briefly, the samples were amplified in $25 \mu \mathrm{l}$ aliquots containing the cDNA $(2 \mu \mathrm{l}), 2 \times$ EasyTaq PCR Supermix $(12.5 \mu \mathrm{l}$; TransGen Biotech, China) and 200 pmol each of the forward and reverse primers. The polymerase was activated at $94^{\circ} \mathrm{C}$ for $5 \mathrm{~min}$, followed by 45 amplification cycles consisting of a denaturation step at $94^{\circ} \mathrm{C}$ for $15 \mathrm{~s}$, annealing at a primer-specific temperature $\left(55^{\circ} \mathrm{C}\right.$ for VIM; $57^{\circ} \mathrm{C}$ for K10) for $20 \mathrm{~s}$ with a ramping rate of $2^{\circ} \mathrm{C} / \mathrm{s}$, and an extension step at $72^{\circ} \mathrm{C}$ for $20 \mathrm{~s}$. The specificity analysis of the PCR products was performed immediately after PCR using $2 \%$ agarose gel electrophoresis, with the resulting image scanned by the BINTA 2020D gel imaging system (FluorChem SP, USA). RNA extracted from $\mathrm{HaCaT}$ cells, which were cultured in DMEM, was used as a positive control for keratin.

The fibroblasts were incubated on coverslips in 24-well plates for at least $48 \mathrm{~h}$. The cells were then fixed in $4 \%$ paraformaldehyde at $4^{\circ} \mathrm{C}$ for $20 \mathrm{~min}$. The coverslips were washed three times in phosphate-buffered saline (PBS) and air dried. For intracellular staining, the cells were permeabilised in $0.15 \%$ Triton X-100$5 \%$ BSA-PBS at room temperature for $20 \mathrm{~min}$, followed by two extensive washes with PBS. The cells were then incubated in $3 \% \mathrm{H}_{2} \mathrm{O}_{2}$ for 10 min to eliminate endogenous peroxidase and again washed in PBS three times. The cells were incubated at $4^{\circ} \mathrm{C}$ for $2 \mathrm{~h}$ with the primary mouse monoclonal anti-vimentin 9 (1:100; Santa Cruz Biotechnology) and anti-keratin (1:100, Santa Cruz Biotechnology) antibodies and then washed twice in PBS-T $(0.1 \%$ Tween-20) for $10 \mathrm{~min}$. The cells were further incubated with a FITC-labelled sheep anti-mouse IgG secondary antibody (1:100; Vector, USA) and $10 \mu \mathrm{l}$ propidium iodide at room temperature for $2 \mathrm{~h}$. The stained cells were then washed with PBS-T and visualised using an inverted microscope (Nikon TE300). When the fibroblasts were identified, all the experiment following were preformed three times.

\section{UVB irradiation}

A Waldmann UV 208T (HerbertWaldmann GmbH \& Co., Villingen-Schwenningen, Germany) with a peak emission at $313 \mathrm{~nm}$ was used for the UVB irradiation. The UVB output was measured using a Waldmann UV Meter (HerbertWaldmann GmbH \& Co.). The UVB irradiation dose was controlled by adjusting the exposure time. Prior to irradiation, the cells were rinsed twice with pre-warmed PBS after removal of the media. The cell exposure to the UVB irradiation was performed in petri dishes containing PBS without sodium bicarbonate, which was immediately replaced by fresh DMEM containing 10\% FBS after the UVB irradiation. The UVB irradiation dosages used in this 
study were $0,25,50,75,100$, and $125 \mathrm{~mJ} / \mathrm{cm}^{2}$. The temperature was kept constant during the irradiation procedure. The controls followed the same schedule of media changes without the UVB irradiation.

\section{RNA extraction}

Total RNA was extracted from the fibroblasts $24 \mathrm{~h}$ after exposure to the different doses of UVB using TRIzol Reagent (Invitrogen, USA). In addition, total RNA was extracted from fibroblasts $12,24,36$, and 48 $\mathrm{h}$ after exposure to a UVB dose of $125 \mathrm{~mJ} / \mathrm{cm}^{2}$. Genomic DNA contamination was removed by on-column digestion using the RNAse-free DNase set (Qiagen, Germany). A Nanodrop ND1000 spectrophotometer (Gene, American) was employed to analyse the RNA concentration and purity. The absence of inhibitors was tested using 10-fold serial dilutions of pooled target gene cDNA. The integrity of the isolated total RNA was assessed with the RNA 6000 Nano LabChip ${ }^{\circledR}$ kit using the Agilent 2100 Bioanalyzer (Agilent Technologies, USA). The Agilent 2100 Expert software was used to generate a so-called RNA Integrity Number (RIN) as an indicator of the RNA quality for downstream experiments. All samples were stored at $-80^{\circ} \mathrm{C}$ and utilised within 2 months.

\section{cDNA synthesis}

Purified and frozen RNA (800 ng) was reverse-transcribed in a $20 \mu \mathrm{l}$ mixture using the RevertAid ${ }^{\mathrm{TM}}$ First Strand cDNA Synthesis Kit Oligo dT Primers (Fermentas, Canada) on a BioRad PTC-200 DNA Engine thermal cycler (BioRad, Hercules, USA). Briefly, the RNA samples and oligo $(\mathrm{dT})$ primers were mixed and denatured at $70^{\circ} \mathrm{C}$ for $10 \mathrm{~min}$. The tubes were then immediately placed on ice for at least $1 \mathrm{~min}$. The transcription mixture and RNase inhibitor were added, and the mixture was incubated at $37^{\circ} \mathrm{C}$ for $5 \mathrm{~min}$. The first-strand cDNA synthesis was started after the addition of M-mulv, and the reverse transcriptase reaction was performed at $42^{\circ} \mathrm{C}$ for $1 \mathrm{~h}$. Finally, the enzymes were inactivated at $70^{\circ} \mathrm{C}$ for $10 \mathrm{~min}$. The reactions were performed in triplicate to reduce any differences in the efficiency of the reverse transcription reaction. The cDNA was stored at $-80^{\circ} \mathrm{C}$ and diluted 1:5 with $\mathrm{RNase}$-free water for use as the template in the real-time PCR analysis.

\section{Primer design}

The primers were designed using Primer 3 software (http://frodo.wi.mit.edu/primer3/) with the following parameters: melting temperature between $57^{\circ} \mathrm{C}$ and $63^{\circ} \mathrm{C}$, length of 20 or $21 \mathrm{bp}, \mathrm{GC}$ content between $45 \%$ and $60 \%$, and production of PCR products between 127 and $205 \mathrm{bp}$. The primers were tested for specificity using NCBI BLAST (http://www.ncbi.nlm.nih.gov/tools/ primer-blast/), and Primer 5 was subsequently used to evaluate the target sequences amplified by the primer pairs to avoid the formation of secondary structures at the primer binding site. Primer specificity was confirmed by $2 \%$ agarose gel electrophoresis (results not shown) and by the melting curve analysis. The primer sequences and expected amplicon sizes are given in Table 2.

\section{Real-time PCR}

The expression study was performed using a 96-well plate on an iQ5 iCycler Multicolor Real-Time PCR detection system (BioRad, Hercules, CA, USA) with the TransStart Green qPCR SuperMix UDG kit (TransGen Biotech, China). The reaction was performed according to the manufacturer's instructions with minor modifications. Briefly, the samples were amplified in $25 \mu \mathrm{l}$ aliquots containing cDNA $(2 \mu \mathrm{l}), 1 \times \mathrm{IQ}$ SYBR Green Supermix and 100 pmol each of the forward and reverse primers. The cycling conditions were $2 \mathrm{~min}$ at $50^{\circ} \mathrm{C}$ for the UDG incubation and $10 \mathrm{~min}$ at $95^{\circ} \mathrm{C}$ for the polymerase activation, followed by 40 cycles of denaturation at $95^{\circ} \mathrm{C}$ for $15 \mathrm{~s}$, annealing at $55^{\circ} \mathrm{C}$ (the annealing temperatures for the different primers are given in Table 2) for $30 \mathrm{~s}$ and extension at $72^{\circ} \mathrm{C}$ for $30 \mathrm{~s}$. The specificity analysis of the PCR products (melting curve analysis) was performed immediately after the real-time PCR. The temperature range used for the melting curve generation was $60^{\circ} \mathrm{C}$ to $95^{\circ} \mathrm{C}$. Each sample was analysed in triplicate wells and was always analysed in one analytical run to avoid between-run variations. Each PCR run included a no-template control using water instead of cDNA.

A 10-fold dilution series was created from a cDNA pool from our sample group (including all samples) ranging from a $10 \times$ dilution to a $100000 \times$ dilution. Triplicate $\mathrm{RT}$-qPCR reactions were carried out for each gene at each dilution. The mean cycle threshold $(\mathrm{Ct})$ values for each dilution were plotted against the $\log _{10}$ of the cDNA input for each gene to generate the efficiency plots. The reaction efficiency for each gene assay was calculated using the following equation: $E=10^{(-1 / \text { slope })}$, where $E$ is the reaction efficiency and 'slope' is the slope of the line generated in the efficiency plot.

\section{Statistical analyses}

The average $\mathrm{Ct}$ value from the triplicate PCR performed for each sample and the average efficiency calculated from all samples for each gene were used. The mean $\mathrm{Ct}$ values of the replicates for each sample were transformed into raw, non-normalised quantities (Q) using the comparative $\Delta C t$ method by the equation $\mathrm{Q}=\mathrm{E}^{\Delta \mathrm{Ct}}$, where $\mathrm{E}$ is the reaction efficiency for each gene assay in question and $\Delta \mathrm{Ct}=\min \mathrm{Ct}-$ sample $\mathrm{Ct}$, where min $\mathrm{Ct}$ is the lowest $\mathrm{Ct}$ value over a range of samples for a 
given assay, and sample $\mathrm{Ct}$ is the $\mathrm{Ct}$ value of the sample being transformed.

All statistical evaluations were carried out using the SPSS (version 17) software package. One-way ANOVA was used to test the gene expression differences between normal and irradiated fibroblasts. Significant results from the ANOVA tests were further analysed by Tukey's posthoc test. $\mathrm{P}<0.05$ was considered significant.

The expression data was analysed using the geNorm algorithm, which determines a reference gene stability factor $(M)$. The stability factor $M$ was defined as the average variation of a particular gene compared with all of the other candidate reference genes. In the final analysis, genes with an $\mathrm{M}$ value lower than 0.5 were considered to be stably expressed genes. The candidate reference gene expression stability was also analysed by the NormFinder programme.

\section{Acknowledgements}

This work was supported by the Youth Foundation of Peking Union Medical College Hospital (No. 2006125), which is a foundation dedicated to supporting young doctors at the beginning of their research, and the foundation supplied all of the funding for this experimental study.

\section{Author details}

'Department of Dermatology, Peking Union Medical College Hospital, Chinese Academy of Medical Sciences \& Peking Union Medical College, Beijing, PR China. ${ }^{2}$ Chinese Academy of Medical Sciences and Peking Union Medical College Institute of Dermatology, Nanjing, PR China.

\section{Authors' contributions}

$\mathrm{LL}$ was the main contributor to the manuscript and performed the majority of the experiments, data analysis and interpretation, and study design. $\mathrm{LL}$ also wrote the majority of the manuscript. YY and HXX collected the samples, participated in the study design and performed some of the experiments. TQ made critical contributions to the data analysis. BXW provided guidance in the study design and assisted with the data analysis. All authors were involved in critically revising the manuscript during its production, and they all read and approved the final manuscript.

Received: 22 August 2010 Accepted: 17 February 2011

Published: 17 February 2011

\section{References}

1. Simić D, Prohić A, Situm M, Zeliko Penavić J: Risk factors associated with the occurrence of basal cell carcinoma. Coll Antropol 2010, 34(1):147-150.

2. Chang NB, Feng R, Gao Z, Gao W: Skin cancer incidence is highly associated with ultraviolet-B radiation history. Int J Hyg Environ Health 2010, 5:358-369.

3. Rana S, Byrne SN, MacDonald LJ, Chan CY, Halliday GM: Ultraviolet B suppresses immunity by inhibiting effector and memory T cells. Am J Pathol 2008, 172(4):993-1004

4. Lee KS, Alvarenga TA, Guindalini C, Andersen ML, Tufik S: Validation of commonly used reference genes for sleep-related gene expression studies. BMC Mol Biol 2009, 10:45.

5. Jung M, Ramankulov A, Roigas J, Johannsen M, Ringsdorf M, Kristiansen G, Jung K: In search of suitable reference genes for gene expression studies of human renal cell carcinoma by real-time PCR. BMC Mol Biol 2007, 8:47.

6. Glare EM, Divjak M, Bailey MJ, Walters EH: Beta-actin and GAPDH housekeeping gene expression in asthmatic airways is variable and not suitable for normalising mRNA levels. Thorax 2002, 57:765-770.

7. Cicinnati VR, Shen QL, Sotiropoulos GC, Radtke A, Gerken G, Beckebaum S: Validation of putative reference genes for gene expression studies in human hepatocellular carcinoma using real-time quantitative RT-PCR. BMC Cancer 2008, 8:350.

8. Wintrebert P: La rotation imme'diate de l'oeuf pondu et la rotation d'activation chez. Discoglossus pictus Otth. Comptes. Rend Soc Biol 1931, 106:439-442

9. Erickson HP: Evolution of the cytoskeleton. Bioessays 2007, 29(7):668-677.

10. Jan L, Amos LA: Evolution of cytomotive filaments: The cytoskeleton from prokaryotes to eukaryotes. Int J Biochem Cell Biol 2009, 41:323-329.

11. Ivaska J, Pallari HM, Nevo J, Eriksson JE: Novel functions of vimentin in cell adhesion, migration, and signaling. Exp Cell Res 2007, 313:2050-2062.

12. Fletcher DA, Mullins RD: Cell mechanics and the cytoskeleton. Nature 2010, 463:485-492

13. Xu HX, Yan Y, Li L, Peng SG, Qu T, Wang BX: Ultraviolet B-induced apoptosis of human skin fibroblasts involves activation of caspase- 8 and -3 with increased expression of vimentin. Photodermatol Photoimmunol Photomed 2010, 26:198-204.

14. Vandesompele J, De Preter K, Pattyn F, Poppe B, Van Roy N, De Paepe A, Speleman F: Accurate normalization of real-time quantitative RT-PCR data by geometric averaging of multiple internal control genes. Genome Biol 2002, 3:research0034.1-11.

15. Tong ZG, Gao ZH, Wang F, Zhou J, Zhang Z: Selection of reliable reference genes for gene expression studies in peach using real-time PCR. BMC Mol Biol 2009, 10:71.

16. Stamova BS, Apperson $1 \mathrm{M}$, Walker WL, Tian YF, Xu HC, Adamczy P, Zhan XH, Liu DZ, Ander BP, Liao IH, Gregg JP, Turner RJ, Jickling G, Lit L, Sharp FR: Identification and validation of suitable endogenous reference genes for gene expression studies in human peripheral blood. BMC Med Genomics 2009, 2:49.

17. Bas A, Forsberg G, Hammarstrom S, Hammarstrom ML: Utility of the housekeeping genes $18 \mathrm{~S}$ rRNA, beta-actin and glyceraldehyde-3phosphate-dehydrogenase for normalization in real-time quantitative reverse transcriptase-polymerase chain reaction analysis of gene expression in human T lymphocytes. Scand J Immunol 2004, 59:566-573.

18. Johansson S, Fuchs A, Okvist A, Karimi M, Harper C, Garrick T, Sheedy D, Hurd Y, Bakalkin G, Ekstrom TJ: Validation of endogenous controls for quantitative gene expression analysis: application on brain cortices of human chronic alcoholics. Brain Res 2007, 1132:20-28.

19. Goidin D, Mamessier A, Staquet MJ, Schmitt D, Berthier-Vergnes O: Ribosomal 18S RNA prevails over glyceraldehyde-3-phos-phate dehydrogenase and beta-actin genes as internal stand-ard for quantitative comparison of mRNA levels in invasive and noninvasive humanmelanoma cell subpopulations. Anal Biochem 2001, 295:17-21.

20. Katina IS, Florian L, Christoph M, John KC, Don G, Michael EP, Ralph T: Predator-induced defences in Daphnia pulex: Selection and evaluation of internal reference genes for gene expression studies with real-time PCR. BMC Mol Biol 2010, 11:50.

21. Yang $X$, Wang J, Liu C: Cleavage of p53-vimentin complex enhances tumor necrosis factor-related apoptosis-Inducing ligand-Mediated apoptosis of rheumatoid arthritis synovial fibroblasts. Am J Pathol 2005, 167(3):705-719.

doi:10.1186/1471-2199-12-8

Cite this article as: Li et al:: Selection of reference genes for gene expression studies in ultraviolet B-irradiated human skin fibroblasts using quantitative real-time PCR. BMC Molecular Biology 2011 12:8.

\section{Submit your next manuscript to BioMed Central and take full advantage of:}

- Convenient online submission

- Thorough peer review

- No space constraints or color figure charges

- Immediate publication on acceptance

- Inclusion in PubMed, CAS, Scopus and Google Scholar

- Research which is freely available for redistribution 